\title{
CORRECTION
}

\section{Correction to: Effect of wood dust type on mechanical properties, wear behavior, biodegradability, and resistance to natural weathering of wood-plastic composites}

\author{
Correction to: Frontiers of Structural and Civil Engineering, 2019, 13(6): 1446-1462 \\ https://doi.org/10.1007/s11709-019-0568-9
}

\author{
Sawan KUMAR ${ }^{a, b}$, Ajitanshu VEDRTNAM ${ }^{a, b, c, d^{*}}$, S. J. PAWAR ${ }^{a}$ \\ ${ }^{a}$ Department of Applied Mechanics, Motilal Nehru National Institute of Technology Allahabad, Allahabad, UP 211004, India \\ ${ }^{b}$ Department of Mechanical Engineering, Invertis University, Bareilly, UP 243001, India \\ ${ }^{c}$ Vinoba Bhave Research Institute, Allahabad, UP 211004, India \\ ${ }^{d}$ Translational Research Centre, Institute of Advanced Materials, VBRI, Linkoping 58330, Sweden \\ *Corresponding author. E-mail: ajitanshu.m@invertis.org
}

(C) Higher Education Press 2021

\begin{abstract}
After publication of our article [1], the authors became aware that they had omitted to include the credit line for Fig. 1 [2]. The corrected Fig. 1 caption with the credit line is given below:

"Fig. 1 (a) Photograph of wood-plastic composite samples; (b) photographs of experimental setups used 1) pin on disk, 2) tensile testing, 3) three-point bending, 4) impact, 5) injection molding, 6) effect of weathering [12]. Reprinted from Construction and Building Materials, 172, Thanate Ratanawilai, Kampanart Taneerat, Alternative polymeric matrices for wood-plastic composites: Effects on mechanical properties and resistance to natural weathering, 349-357, Copyright (2018), with permission from Elsevier."
\end{abstract}

\section{References}

1. Kumar S, Vedrtnam A, Pawar S J. Effect of wood dust type on mechanical properties, wear behavior, biodegradability, and resistance to natural weathering of wood-plastic composites. Frontiers of Structural and Civil Engineering, 2019, 13(6): 1446-1462

2. Ratanawilai T, Taneerat K. Alternative polymeric matrices for wood-plastic composites: Effects on mechanical properties and resistance to natural weathering. Construction and Building Materials, 2018, 172: 349-357 